\title{
A Fundamental Approach to Facilities Location Risk Assessment and Its Relevance to Supply Chain Network Design: Using the Thai Floods of 2011 as an Example
}

\author{
Matthew H. Smith
}

\begin{abstract}
Managing risk in supply chains and facilities location is an important topic. The majority of previous work focusses on inherent risk of disruption within the supply chain. There is less attention paid to the risk of catastrophic events affecting the supply chain, through disruption of one or more facilities. Flooding in Thailand during 2011 had a multi-billion dollar economic impact. This was partially through an under-estimation of the risk flooding posed to the facilities. In many cases simulation of natural disaster impact on a facility location may be the way forward. This paper however proposes a fundamental approach to facilities risk assessment in reference to natural disasters. It suggests four key sets of information can help define the main risk in a timely and economic manner. These are; geolocation, historical data, weather patterns and anthropogenic impacts. This approach will then provide greater confidence in going forward with more detailed analysis of the identified risk. The Thai floods of 2011 are used as a test of the method. The fundamental approach clearly identifies risk of flood as worthy of detailed simulation.
\end{abstract}

Index Terms-Supply chain network design, facilities location, catastrophic event, fundamentals risk assessment.

\section{INTRODUCTION}

Supply chain network (SCN) design and facilities location decision making both take into account the possibility of catastrophic events adversely impacting the manufacturing and/or distribution site.

Examples of such events are varied; from natural disasters to political instability.

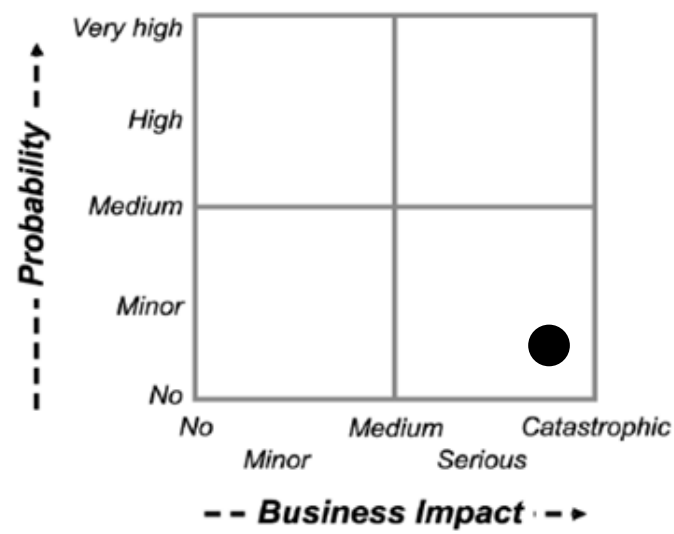

Fig. 1. Probability of adverse event occurring vs. the business impact. Most catastrophic events occur as shown on the figure. (Modified from Knemeyera et al. 2009).

Manuscript received May 18, 2013; revised July 17, 2013.

M. H. Smith is with the Institut Teknologi Brunei, Bandar Seri Begawan, Brunei Darussalam (e-mail: matthew.smith@itb.edu.bn).
Numerous authors (for example [1]-[6]) have investigated how high impact events can be risked as part of SCN design. Typically risk exposure to these events can be seen as a probability these events occurring in combination with the projected impact on the business affected, ie business impact, as in Fig. 1. It is thought that analysis of historical data gives a reasonable degree of certainty for natural disasters, as extreme events tend to occur repeatedly and hence predictably, from a risk perspective. However there are other extreme events that are not so predictable such as civil disturbances, political instability and economic collapse of a country.

SCN design generally does not consider site vulnerability as part of the risk as facilities are usually insured. Experience has shown that losses from business interruption can be significant. For example Western Digital annual reports for the years after the 2011 Thailand floods show that insurance payout does not cover all losses and competitors took advantage of the disruption to increase their market share.

Flooding which occurred in Thailand in 2011 had a serious impact on global supply chains. This paper is a brief review of some of the impacts of the flooding. It offers a method of evaluating risk as a basic starting point for site selection before complex, and expensive, natural disaster simulations are undertaken.

\section{FUNDAMENTAL APPROACH TO FACILITY RISK ASSESSMENT}

Numerous studies appear in literature investigating supply chain risk management (for a review [7]). Risk to the facility location is given little consideration when looking at supply chain risk, as it is thought insurance cover negates the need to include facilities. Risking of facilities location tends to be dealt with separately. Most of this literature is not specifically about catastrophic events (e.g. [8]) and deal with mitigating disruption when it occurs.

A widely cited paper which deals with risking catastrophic events in supply chains is Knemeyer et al. [9]. Their paper has many practical suggestions as to how businesses can assess and plan for catastrophic risk in the supply chain. One recommendation is that a company identifies key locations in its supply chain which, if affected by catastrophe, would have the largest business impact. They suggest that catastrophe simulations should be used as a tool for estimating probability of occurrence.

This approach is acceptable when dealing with existing facilities or when adding existing facilities into the supply chain. However when attempting to select a site for a new 
facility, to undertake numerous simulations for all potential sites would incur significant costs and time delays.

Selection criteria for facility location are numerous, but for most companies having a low risk of natural catastrophes is not of a particularly high priority. For companies originating in disaster prone countries, such as Japan, it may be a higher priority however.

The catastrophic floods that occurred in Thailand during the monsoon season of 2011, which will be discussed in more detail later in this paper, clearly demonstrated that assessment of the risk of disruption to facilities was massively underestimated or not carried out. This fact is not necessarily alarming as insurance companies would want to do their own risk assessment as part of setting the premium levels for purchased cover. However in the aftermath of the Thai floods it was shown that the risk exposure was significantly underestimated [10].

This may be because some assessments focus on historical data of insurance payouts and their reasons. While this approach is clearly valid the context must be considered. In mature developed economies this may prove reasonably robust. However in developing countries with only a couple of decades of integration into the global supply chains it would present only a dangerously small sub-set of data from which to draw conclusions. This point has obviously been recognised for some time, with many specialist forecasting companies offering services to the insurance industry. Coming back to the earlier point however, in the case of the Thai floods, which ever approach was used proved to be inadequate.

One question that follows from this is; when evaluating numerous potential locations is there an inexpensive, fast and simple method to help focus management perception on facility location risk?

The author suggests a basic approach to understanding potential for natural disaster at a given location. If this approach is carried out for numerous potential sites, an initial selection can occur so that a smaller number of preferred locations can be subject to more detailed numerical analysis. For an existing facility the same approach can be utilised to identify the most obvious risk, e.g. earthquake, flood or hurricane etc., which can then be subject to detailed analysis and simulation.

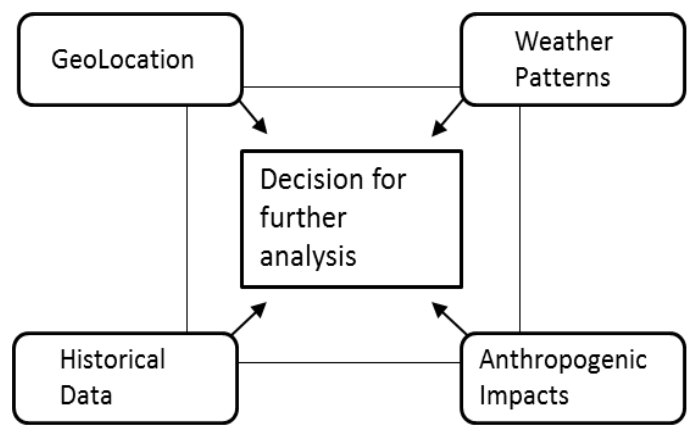

Fig. 2. Knowledge inputs used in fundamental analysis.

Fig. 2 shows four core knowledge nodes that must be populated with information to make an initial judgment on the range of natural disasters that are likely for a given location. Section III will use the 2011 floods in Thailand as a case study. The information required for populating each node is mostly available for free from numerous sources such as libraries, web-sites and computer applications.

\section{A. GeoLocation}

What is the geology and physical geography present in the area of interest? For example, is the location over a sedimentary basin, close to bedrock, radon releasing rocks etc. Is it close to active faults which lead to earthquakes or in the vicinity of volcanoes, etc. Is it located on a river flood plain, an upland plateau, a river delta, etc.?

All these underlying factors are the cause of certain natural disasters and hence must be evaluated.

\section{B. Historical Data}

Historical data of previous insurance claims has widespread use in the industry, but its use here is limited. More so the historical occurrence of natural disasters, irrespective of the economic loss, needs to be looked at, to see how it fits with the other three nodes.

\section{Weather Patterns}

What is the overall weather patterns for a given location. Is the risk more from drought and fire, or from seasonal intense rain storms. Is the area in a typhoon/hurricane prone area? Is the weather in the area reasonably consistent or given to significant variation through time?

\section{Anthropogenic Impacts}

How much have people changed the environment in the area of interest? For example has a dam changed the behavior of a nearby river, or has deforestation increased run-off and the threat of landslides?

\section{THAI FLOODS OF 2011: OVERVIEW AND USE AS A VERIFICATION OF THE PROPOSED METHOD}

In the second half of 2011 Thailand experienced some of its worst flooding for 70 years. Along with its impact on human life and residential property, the flood waters affected several large industrial estates in the central areas of Thailand. This impacted on many industries, but notably automotive and electronic. The economic cost is estimated at US\$45bn with an insured loss of US\$15.5bn [11], making it the fifth largest economic loss from a natural disaster since 1950 and the largest loss from a flooding event since 1950.

Fragmentation and agglomeration trends, together with just-in-time production meant that complex supply chains were vulnerable to disruption at a single node [12]. Hence the massive scale of disruption and financial loss from the flood.

According to the chairman of Willis Re (a leading reinsurance advisory group) "One of the most difficult losses the global industry has had to manage is the flood loss which occurred in Thailand at the end of 2011." "Exposures were significantly underestimated, especially as regards the extent of global connections across sophisticated supply chains." [10]. In addition to its global supply chain exposure, the country's flood hazard had not been modelled and was poorly understood and appreciated.

Adityam Krovvidi explained; (head of Aon Benfield's Impact Forecasting in Asia Pacific) "Of all the cat perils, flood is the most frequent to occur and the most complex to 
model," ("This is due to its varied phenomena, ever increasing human interventions and climate variability"). "Notwithstanding these factors, Thailand had no major flood loss experience before 2011 to receive the attention of the insurance industry." "A little more rain than the historical maximum in the northern region led to a 'perfect storm' last year, aided by man-made factors. The event was not a 'Black Swan' - the industry simply never paid sufficient attention to potential flood risk - we were simply fooled by historical experience" [10].

The Thai floods of 2011 seem an ideal example to try a fundamental risk assessment approach as it demonstrated the risk of natural disaster affecting the sites was clearly underestimated. The area around Ayutthaya was particularly affected due to the concentration of industrial estates. This location will be used for the example/case study.

\section{A. GeoLocation}

Geology - Area is underlain by a tertiary rift basin, the Ayutthaya Basin, which is no longer active but has some thermal subsidence (e.g. [13]). This means that the area could be susceptible to subsidence as the 'bed rock' is very deep from the surface. The landscape is flat with little elevation. The area is not susceptible to earthquakes or volcanic hazards.

Physical Geography - Area is located on the flood plain of the Chao Phraya River. This is a major tropical river in SE Asia, its flood plain covers large parts of central mainland Thailand and its delta from north of Ayutthaya to the Gulf of Thailand. The yearly flooding of the river gave rise to the fertile agricultural areas of central Thailand. It is characterised by widespread flooding. [14] The area has mostly been cleared of trees and poses little risk of natural wild fires. Equally landslide risk is low due to subdued topography.

\section{B. Historical Data}

Insurance Claims - Data is not generally available in sufficient detail (as noted in section above, data did not reflect significant prior claims from natural hazards)

Natural Disaster Data - No earthquake, volcano or landslide hazard. Typhoon risk in the area is minimal, potential of increased rainfall. Floods are common in numerous areas of central Thailand annually.

\section{Weather Patterns}

Tropical climate - Normal weather pattern has a hot dry period followed by the wet 'rainy season' around Late May to June (tropical wet and dry). Occasionally get droughts or wetter years. Like most locations there is potential for higher than historical average events. Tropical Typhoons tend to affect peninsula Thailand or the far north of Thailand directly. The area under investigation can be affected by enhanced rainfall from distant typhoons.

\section{Anthropogenic Impacts}

Local Changes - Over last couple of decades or more there has been a change in land use from agriculture to industrial in the location. This leads to faster rain run off times to the river system and less open land to 'soak up' water. If managed properly this should not be a significant factor, but given the flat topography drainage needs to be well engineered.

Regional Changes - Construction of dams upstream reduce the supply of sediment, hence enhancing subsidence. Deforestation up stream leads to enhanced rain water run-off to rivers.

\section{E. Decision for Further Analysis}

The anthropogenic impacts and historical data give no particular cause for concern. Ayutthaya's physical geography, coupled with normal weather patterns however, give cause for concern. The industrial sites near Ayutthaya are located within several kilometers of the Chao Phraya River channel on its' flood plain. The river floods every year along different parts of its course. There are several areas which do not seem to flood as they are on higher ground, which correspond to different geology. The Ayutthaya area however is flat and sits on top of a rift basin. Hence the outcome of the fundamentals summary is that flood is a clear risk, and given Ayutthaya's location the risk will slowly increase in the future. The recommendation would be to carry out detailed flood simulations for the facility location.

\section{CONCLUSION}

The qualitative fundamental risk analysis used is one method to help focus attention on underlying location risk. With this information initiation of more detailed analysis can be undertaken with more confidence. Although a qualitative analysis, it is thought with some modification a quantitative assessment can be made using the same basic approach.

\section{REFERENCES}

[1] A. Norman and U. Jansson, "Ericsson's proactive supply chains risk management approach after a serious sub-supplier accident," International Journal of Physical Distribution \& Logistics Management, vol. 34, no. 5, pp. 434-447, 2004.

[2] Y. Sheffi, Supply Chain Management under the Threat of International Terrorism, The International Journal of Logistics Management, vol. 12, no. 2, pp. 1-11, 2001.

[3] Y. Sheffi, The Resilient Enterprise: Overcoming Vulnerability for Competitive Advantage, MIT Press Books, 2005.

[4] E. Banks, Catastrophic Risk: Analysis and Management, Wiley Finance, 2006

[5] S. Kaplan, "Applying the general theory of quantitative risk assessment (QRA) to terrorism risk," in Risk-Based Decision Making in Water Resources X: Proceedings of the Conference, ASCE Publications, 2002.

[6] J. H. Lambert, M. Asce, and P. Sarda, "Terrorism scenario identification by superposition of infrastructure networks," Journal of Infrastructure Systems, vol. 11, no. 2, pp. 211-220, 2005.

[7] P. Singhal, G. Agarwal, and M. L. Mittal, "Supply chain risk management: review, classification and future research directions," International Journal of Business Science and Applied Management, vol. 6, pp. 15-42, 2011.

[8] L. V. Snyder and M. S. Daskin, "Reliability models for facility location: the expected failure cost case," Transportation Science, vol. 39, no. 3, pp. 400-416, 2005.

[9] M. Knemeyera, W. Zinna, and C. Eroglub, "Proactive planning for catastrophic events in supply chains," Journal of Operations Management, vol. 27, pp. 141-153, 2009.

[10] Lloyds. Learning from the Thai floods. [Online]. Available: http://www.lloyds.com/news-and-insight/news-and-features/environm ent/environment-2012/learning-from-the-thai-floods

[11] A. Benfield, "Annual global climate and catastrophe report impact forecasting," 2012.

[12] A. Chongvilaivan, "Thailand's 2011 flooding: Its impact on direct exports, and disruption of global supply chains," ARTNeT Working Paper, Bangkok, ESCAP, no. 113, 2012. 
[13] M. Smith, S. Chantraprasert, C. K. Morley, and I. Cartwright, "Structural geometry and timing of deformation in the Chainat duplex, Thailand," in Cunningham, \& Mann, (eds. Tectonics of Strike-Slip Restraining and Releasing Bends, Geological Society London, Special Publications, vol. 290, pp. 305-323, 2007.

[14] J. P. M. Syvitski, I. Overeem, G. R. Brakenridge, and M. Hannon, "Floods, floodplains, delta plains-A satellite imaging approach," Sedimentary Geology, vol. 267-268, pp. 1-14, 2012.
Matthew H. Smith was born in Great Britain in 1977. He obtained a B.Sc. with Honours in Geology, University of Southampton in 1998; M.Sc. in Mineral Exploration, University of Leicester in 1999. He currently works a the Institut Teknologi Brunei as a senior lecturer in the faculty of engineering. Smith is a member of the European Association of Geoscientists and Engineers. Smiths' research interests are varied, but mostly focus on petroleum geoscience and engineering. He also looks for areas where geoscience knowledge can further understanding in a trans-disciplinary approach. 